\title{
A novel frameshift mutation in UPF3B identified in brothers affected with childhood onset schizophrenia and autism spectrum disorders
}

AM Addington, J Gauthier, A Piton, FF Hamdan, A Raymond, N Gogtay, R Miller, J Tossell, J Bakalar, G Germain, P Gochman, R Long, JL Rapoport and GA Rouleau

Molecular Psychiatry (2012) 17, 468; doi:10.1038/mp.2010.76; published online 7 September 2010

Correction to: Molecular Psychiatry (2011) 16, 238-239; doi:10.1038/mp.2010.59; published online 18 May 2010

After the article was published online, the authors noted G Germain's name was incomplete in the author list. The corrected author list appears below:

AM Addington, J Gauthier, A Piton, FF Hamdan, A Raymond, N Gogtay, R Miller, J Tossell, J Bakalar, G Inoff-Germain, P Gochman, R Long, JL Rapoport and GA Rouleau

\section{A neuropeptide S receptor variant associated with overinterpretation of fear reactions: a potential neurogenetic basis for catastrophizing}

KA Raczka, N Gartmann, M-L Mechias, A Reif, C Büchel, J Deckert and R Kalisch

Molecular Psychiatry (2012) 17, 468; doi:10.1038/mp.2010.114

Correction to: Molecular Psychiatry (2010) 15, 1067-1074; doi:10.1038/mp.2010.79; published online 13 July 2010
After the online publication of the above paper, the authors noticed that Figure 1 was incorrect. The corrected figure appears below:
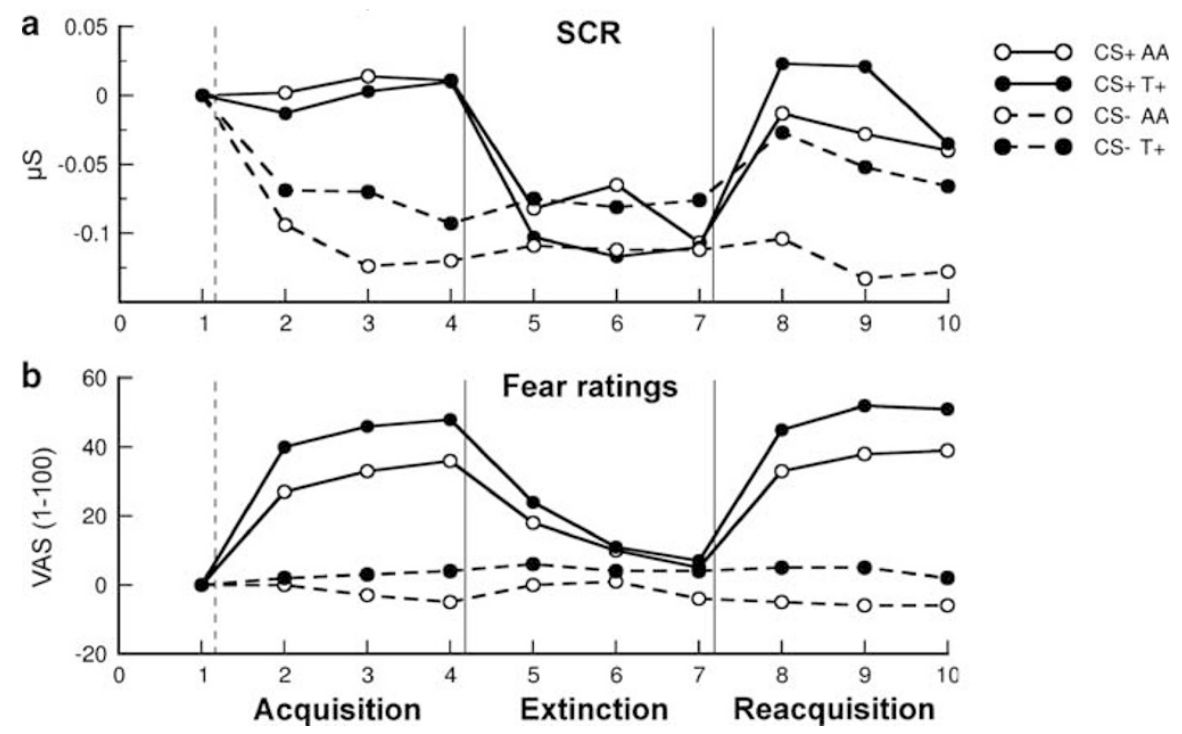